\title{
Model Produktivitas Usahatani Padi Ciherang Di Desa Hambuku Hulu Kecamatan Sungai Pandan Kabupaten Hulu Sungai Utara
}

\author{
(Farmbussines Productivity Ciherang Paddy In Hambuku Hulu Village \\ Sungai Pandan District Hulu Sungai Utara Regency)
}

\author{
Azwar Saihani $^{1)}$ \& Erni Mustika ${ }^{2)}$ \\ Program Studi Agribisnis, Sekolah Tinggi Ilmu Pertanian Amuntai \\ ${ }^{1)}$ Azwar.saihani63@yahoo.com \\ ${ }^{2)}$ ernimsk@gmail.com
}

\begin{abstract}
ABSTRAK
Penelitian ini bertujuan untuk mengetahui pengaruh faktor-faktor produktivitas terhadap produktivitas usahatani Padi Ciherang di Desa Hambuku Hulu Kecamatan Sungai Pandan, untuk mengetahui faktor-faktor apa yang berpengaruh nyata terhadap produktivitas usahatani Padi Ciherang di Desa Hambuku Hulu Kecamatan Sungai Pandan dan untuk mengetahui bagaimana produktivitas usahatani Padi Ciherang di Desa Hambuku Hulu Kecamatan Sungai Pandan. Penelitian ini dilaksanakan di Desa Hambuku Hulu Kecamatan Sungai Pandan. Metode pengumpulan data dilakukan dengan metode survey dan wawancara. Jumlah petani responden yang diambil dalam penelitian ini berjumlah 52 orang responden. Faktor yang diuji yang dianggap mempengaruhi terhadap produktivitas usahatani Padi Ciherang adalah faktor luas lahan, benih, pupuk dan pestisida. Hasil penelitian menunjukan bahwa nilai $F$ hitung yang terdapat pada tabel Anova adalah sebesar 4,032 dengan nilai signifikan 0,007, jadi nilai signifikan sebesar 0,007 <0,05 sehingga HO ditolak dan Ha diterima, artinya faktor-faktor yang dianggap mempengaruhi yaitu faktor luas lahan, benih, pupuk dan pestisida secara simultan berpengaruh nyata terhadap produktivitas usahatani Padi Ciherang. Nilai Adjusted R2 yaitu sebesar 0,192 menunjukan bahwa pengaruh faktor luas lahan, benih, pupuk dan pestisida terhadap produktivitas usahatani Padi Ciherang adalah sebesar 19,2 \% dan 80,8\% dipengaruhi oleh faktor lain yang tidak termasuk dalam modal regresi. Hasil pengujian koefisien-koefisien regresi secara parsial menunjukan bahwa faktor-faktor yang mempunyai pengaruh nyata terhadap produktivitas usahatani Padi Ciherang adalah faktor pupuk sedangkan faktor luas lahan, benih dan pestisida berpengaruh tidak nyata terhadap produktivitas usahatani Padi Ciherang. Rata-rata produktivitas usahatani Padi Ciherang di Desa Hambuku Hulu adalah 46,74 Kw/ha dapat dikatakan baik dengan rata-rata produksi 80,06 Kw dan rata-rata luas lahan $1,68 \mathrm{Ha}$.
\end{abstract}

Kata kunci : Produktivitas, usaha tani, padi, ciherang, regresi.

\section{ABSTRACT}

This study aims to determine the influence of these factors on the productivity of farm productivity in Rice Ciherang The Hambuku Hulu Village Sungai Pandan District, to determine what factors significantly affect the productivity of Rice Ciherang farming in the Hambuku Hulu Village Sungai Pandan District and to how farm productivity of Rice Ciherang in the Hambuku Hulu Village Sungai Pandan District. The research was conducted in the village of Upper Hambuku Hulu Vilage Sungai Pandan District. Methods of data collection is done by survey and interview methods. The number of farmers respondent taken in this study is 52 peoples. Factors tested were considered to affect the productivity of rice farming is a factor Ciherang land, seeds, fertilizers and pesticides. The results showed that calculated $F$ value contained in the Anova table is equal to 4,032 with significant value of 0,007, so the significant value of 0,007 < 0,05 so HO is rejected and Ha is accepted, it means the factors that are considered are the factors affecting land, seeds, fertilizers and pesticides simultaneous significant effect on the productivity of Rice farming Ciherang. Adjusted $R^{2}$ value of 0,192 indicates that the influence of land, seeds, fertilizers and pesticides to the rice farm productivity Ciherang amounted to 19,2\% and 80,8\% influenced by other factors not included in the regression of capital. The test results of regression coefficients showed that partial factors that have a real impact on the productivity of rice farming is a factor Ciherang fertilizer while the factors of land, seeds and pesticides are not a real effect on the productivity of rice farming 
Ciherang. The average productivity of Rice Ciherang farming in the Hambuku Hulu Village is 46,74 Kw/ha can be said to be good with an average production of 80,06 $\mathrm{Kw}$ and the average land area of 1,68 $\mathrm{Ha}$.

Keywords : Productivity, farming, rice, ciherang, regression.

\section{PENDAHULUAN}

Kabupaten Hulu Sungai Utara merupakan penghasil padi di wilayah Provinsi Kalimantan Selatan. Pada tahun 2012 di Kabupaten Hulu Sungai Utara luas tanaman komoditi Padi Ciherang adalah 25,038 ha dengan luas panen 224,922 ha, produksi sebesar 139,720 ton produktivitas sebesar $56,06 \mathrm{kw} / \mathrm{ha}$. Data luas tanam, luas panen, produksi, dan produktivitas Padi Ciherang Kabupaten Hulu Sungai Utara tahun 2012 dapat dilihat pada Tabel 1 berikut ini:

Tabel 1. Data luas tanam, luas panen, produksi dan produktivitas Padi Ciherang Kabupaten Hulu Sungai Utara tahun 2012

\begin{tabular}{lcccrc}
\hline \multicolumn{1}{c}{ Kecamatan } & $\begin{array}{c}\text { Luas } \\
\text { Tanam } \\
\text { (Ha) }\end{array}$ & $\begin{array}{c}\text { Luas } \\
\text { Panen } \\
\text { (Ha) }\end{array}$ & $\begin{array}{c}\text { Rusak } \\
\text { (Ha) }\end{array}$ & $\begin{array}{c}\text { Produksi } \\
\text { (Ton) }\end{array}$ & $\begin{array}{r}\text { Produktivit } \\
\text { as (Kw/Ha) }\end{array}$ \\
\hline Danau Panggang & 2,525 & 2,525 & - & 14,139 & 55,99 \\
Paminggir & 127 & 127 & - & 708 & 55,76 \\
Babirik & 5,298 & 5,298 & - & 30,07 & 56,76 \\
Sungai Pandan & 3,022 & 3,005 & 17 & 16,841 & 56,04 \\
Sungai Tabukan & 2,345 & 2,345 & - & 13,105 & 55,89 \\
Amuntai Selatan & 2,377 & 2,377 & - & 13,272 & 55,83 \\
Amuntai Tengah & 2,350 & 2,251 & 99 & 12,552 & 55,76 \\
Banjang & 3,455 & 3,455 & - & 19,156 & 55,44 \\
Amuntai Utara & 1,929 & 1,929 & - & 10,851 & 56,25 \\
Haur Gading & 1,610 & 1,610 & - & 9,023 & 56,05 \\
\hline \multicolumn{1}{c}{ Jumlah } & 25,038 & 24,922 & 116 & 139,720 & 56,06
\end{tabular}

Sumber : Dinas Pertanian Tanaman Pangan dan Hortikultura Kabupaten Hulu Sungai Utara, 2012.

Di Kecamatan Sungai Pandan terdapat 33 desa yang membudidayakan tanaman Padi Ciherang sebagai bahan makanan pokok bagi masyarakat khususnya Desa Hambuku Hulu. Desa Hambuku Hulu adalah desa yang produktivitas Padi Ciherang paling tinggi dibandingkan dengan desa-desa yang lain yang berada di Kecamatan Sungai Pandan.
Namun hasil produktivitas Padi Ciherang di Desa Hambuku Hulu selama 3 tahun terakhir mengalami fluktuasi. Data perkembangan hasil produksi dan produktivitas Padi Ciherang di Desa Hambuku Hulu selama 3 tahun terakhir dapat dilihat pada Tabel 2 berikut ini.

Tabel 2. Data perkembangan produksi dan produktivitas Padi Ciherang di Desa Hambuku Hulu tahun 2010-2012

\begin{tabular}{ccc}
\hline Tahun & Produksi (Ton) & Produktivitas (Kw/Ha) \\
\hline 2010 & 938,6 & 64,2 \\
2011 & 921,4 & 62,6 \\
2012 & 963,2 & 66,8 \\
\hline
\end{tabular}

Sumber: Balai Penyuluhan Kecamatan Sungai Pandan, 2012. 
Berdasarkan Tabel 2 diatas terlihat bahwa hasil produktivitas Padi Ciherang pada tahun 2010 sebesar 64,2 kw/ha dan terjadi penurunan pada tahun 2011 yaitu 62,6 kw/ha. Pada tahun 2012 hasil produktivitas Padi Ciherang mengalami peningkatan yaitu sebesar 66,8 ha.

Produktivitas merupakan hasil bagi antara output yang diperoleh dengan besarnya input yang digunakan untuk memperoleh output. Istilah produktivitas secara ekonomis menggambarkan suatu perbandingan antara keluaran dan masukan (Sinungan, 2008). Suatu produktivitas akan berfungsi ketika terdapat beberapa faktor yang mempengaruhi output produksi. Dalam sektor pertanian, terdapat beberapa faktor yang dapat mempengaruhi produktivitas usahatani yaitu diantaranya luas lahan, benih, pupuk dan pestisida.

Analisis regresi menjelaskan hubungan dua atau lebih variabel sebab-akibat. Artinya variabel yang satu akan mempengaruhi variabel lainnya. Besarnya pengaruh variabel ini dapat diduga dengan besaran yang ditunjukkan oleh koefisien regresi.

Analisis regresi berganda adalah suatu teknik yang digunakan untuk membangun suatu persamaan yang menghubungkan antara variabel tidak bebas (Y) dengan variabel bebas (X) dan sekaligus untuk menentukan nilai ramalan atau dugaannya dengan persamaan :

$\mathrm{Y}=\mathrm{b} 0+\mathrm{b} 1 \mathrm{X} 1+\mathrm{b} 2 \mathrm{X} 2+\mathrm{b} 3 \mathrm{X} 3+\mathrm{b} 4 \mathrm{X} 4+$. $\ldots \ldots+b n X n+\varepsilon$

\section{METODE PENELITIAN}

Tempat dan Waktu Penelitian

Penelitian ini dilaksanakan di Desa Hambuku Hulu Kecamatan Sungai Pandan Kabupaten Hulu Sungai Utara. Waktu penelitian dimulai dari bulan Mei 2013 - Juli 2013 mulai dari persiapan, pengumpulan data, pengolahan data sampai dengan penyusunan laporan.

Jenis dan Sumber Data

Penelitian ini menggunakan dua jenis data yaitu data primer dan data sekunder. Data primer merupakan data yang didapat
Dimana : $Y=$ Variabel dependen (variabel terikat), b0 = Intersep, b1 = Koefisien regresi untuk X1, b2 = Koefisien regresi untuk X2, b3 = Koefisien regresi untuk X3, b4 = Koefisien regresi untuk $\mathrm{X} 4$, bn $=$ Koefisien regresi untuk Xn dan $\varepsilon=$ disturbance or error (Suharyadi, 2004).

Secara keseluruhan faktor- faktor yang dianggap mempengaruhi yaitu faktor luas lahan, pendidikan, pengalaman, teknologi, modal dan jumlah tanggungan keluarga tidak terdapat pengaruh yang nyata terhadap produktivitas jagung, secara individu atau masing-masing faktor- faktor yang tidak berpengaruh nyata terhadap produktivitas jagung adalah faktor luas lahan, pendidikan, pengalaman, modal, dan jumlah tanggungan keluarga. Sedangkan faktor yang berpengaruh nyata terhadap produktivitas jagung adalah variabel teknologi. Rata-rata produktivitas usahatani jagung di Desa Pulau Damar adalah 30,98 kw/Ha dapat dikatakan berproduktivitas baik dengan rata-rata produksi $32,88 \mathrm{kw}$ dan rata-rata luas lahan 1,08 Ha (Pratiwi, 2012).

Tujuan penelitian ini mengetahui (i) pengaruh faktor-faktor produktivitas terhadap produktivitas usahatani Padi Ciherang di Desa Hambuku Hulu Kecamatan Sungai Pandan, (ii) faktor-faktor apa yang berpengaruh nyata terhadap produktivitas usahatani Padi Ciherang di Desa Hambuku Hulu Kecamatan Sungai Pandan dan (iii) produktivitas usahatani Padi Ciherang di Desa Hambuku Hulu Kecamatan Sungai Pandan.

dari sumber pertama, misalnya dari individu atau perseorangan. Metode pengumpulan data primer yang dipakai penelitian ini adalah metode survei, yaitu data yang dikumpulkan merupakan sebagian kecil dari populasi yang akan diteliti. Pelaksanaannya dengan menggunakan metode wawancara. Data sekunder merupakan data primer yang telah diolah lebih lanjut menjadi bentuk seperti tabel, grafik, gambar dan sebagainya sehingga lebih informatif oleh pihak lain. Untuk penelitian ini, data sekunder diperoleh dari berbagai sumber, seperti buku-buku referensi, BPS Kabupaten Hulu Sungai Utara, Balai Penyuluhan Kecamatan Sungai 
Pandan, Dinas Pertanian Tanaman Pangan dan Hortikutura, penelitian kepustakaan dan internet.

Metode Penarikan Sampel

Populasi dalam penelitian ini adalah seluruh petani Padi Ciherang yang ada di Desa Hambuku Hulu Kecamatan Sungai Pandan yang berusahatani Padi Ciherang yaitu sebanyak 109 orang petani. Ukuran sampel yang diambil menggunakan rumus Slovin:

$\mathrm{n}=\frac{\mathrm{N}}{1+\mathrm{N}\left(\mathrm{e}^{2}\right)}$

Di mana: $\mathrm{N}=$ Jumlah populasi, $\mathrm{n}=$ Jumlah sampel, $\mathrm{e}=$ kesalahan pengambilan sampel ditetapkan sebesar $10 \%$.

Hasil perhitungan:

$\mathrm{n}=\frac{109}{1+109\left(0,1^{2}\right)}=\frac{109}{1+109(0,01)}=52,15311 \approx$ 52 responden

Metode Pengumpulan dan Analisis Data

Metode pengumpulan data dalam penelitian ini dilakukan dengan metode survei dan wawancara. Survei adalah pengumpulan data yang hanya dilakukan

\section{HASIL DAN PEMBAHASAN}

Uji Asumsi Klasik

1. Uji Multikolinieritas.

Multikolinieritas dalam penelitian ini diukur berdasarkan tingkat Variance pada sebagian dari populasi. Sedangkan wawancara adalah proses pencatatan dengan maksud untuk mengkonstruksi mengenai orang, kejadian, kegiatan, organisasi, dan sebagainya (Nazir, 2005).

Analisis data yang digunakan pada penelitian ini adalah analisis regresi berganda, Uji Asumsi Klasik, Uji Statistik F (Uji Serentak), Koefisien Determinasi $\left(\mathrm{R}^{2}\right)$, Uji Statistik t (Uji Individual/Parsial) dan untuk menghitung produktivitas usahatani Padi Ciherang menggunakan rumus produktivitas yaitu:

$$
\mathrm{PR}=\frac{\mathrm{Y}}{\mathrm{X}}
$$

Dimana : $\mathrm{PR}=$ Produktivitas usahatani Padi Ciherang (Kw/ha)

$\mathrm{Y}=$ Output atau hasil panen/produksi usahatani Padi Ciherang $(\mathrm{Kw})$

$\mathrm{X}=$ Input atau luas lahan usahatani Padi Ciherang (Ha)

Inflation Factor (VIF) dan nilai Tolerence. Nilai tolerance yang dipakai adalah tolerance 0,10 atau sama dengan nilai VIF 10. Jika nilai VIF <10 maka model dinyatakan tidak mengandung gejala multikolinieritas.

Tabel 3. Hasil uji multikolinieritas

\begin{tabular}{lccc}
\hline Variabel & Tolerance & Nilai VIF & Keterangan \\
\hline Luas lahan & 0,163 & 6,136 & Tidak Terjadi Multikolinieritas \\
Benih & 0,139 & 7,173 & Tidak Terjadi Multikolinieritas \\
Pupuk & 0,610 & 1,640 & Tidak Terjadi Multikolinieritas \\
Pestisida & 0,585 & 1,710 & Tidak Terjadi Multikolinieritas \\
\hline
\end{tabular}

Sumber: Pengolahan Data Primer Tahun 2013

Berdasarkan Tabel 2 terlihat bahwa nilai VIF dari masing-masing model <10. Hal ini menunjukan bahwa

2. Uji Heteroskedastisitas

Deteksi adanya heteroskedastisitas dapat dilakukan dengan mengamati scatterplot dimana sumbu horizontal menggambarkan nilai Predicted Standardized sedangkan sumbu vertikal model regresi yang dibentuk tidak ada gejala multikolinieritas.

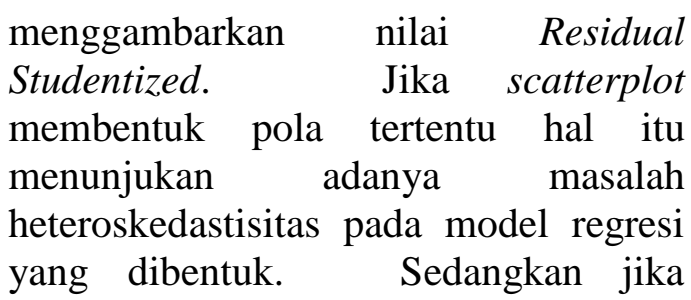


scatterplot menyebar secara acak maka hal itu menunjukan tidak terjadi masalah heteroskedastisitas pada model regresi yang dibentuk.

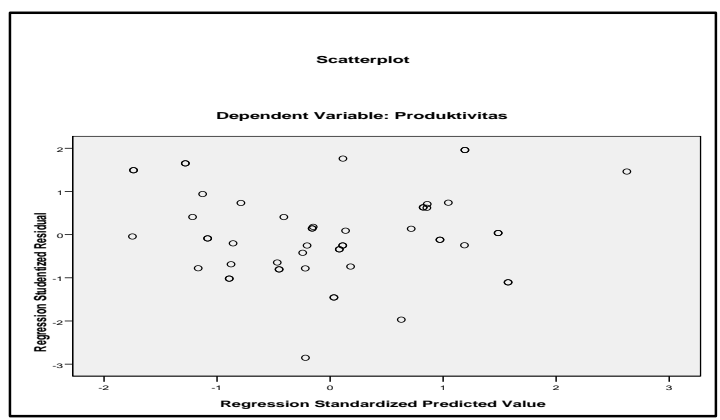

Gambar 2. Hasil uji heteroskedastisitas.

Berdasarkan Gambar 2 terlihat bahwa titik-titik scatterplot menyebar secara acak dan tidak membentuk pola tertentu. Hal ini menunjukan bahwa model regresi yang dibentuk tidak terdapat masalah heteroskedastisitas.

3. Uji Autokorelasi

Ada tidaknya autokorelasi dalam penelitian ini dideteksi dengan menggunakan uji Durbin Watson (D).
Kriteria pengambilan kesimpulan adalah sebagai berikut :

a. Jika nilai $\mathrm{D}$ tepat sama dengan 2 maka tidak terjadi autokorelasi sempurna.

b. Jika nilai $\mathrm{D}$ antara 1,5 sampai 2,5 maka data tidak mengalami autokorelasi.

c. Jika nilai $\mathrm{D}=0$ sampai 1,5 maka memiliki autokorelasi positif.

d. Jika nilai $\mathrm{D}>2,5$ sampai 4 maka memiliki autokorelasi negatif.

Tabel 4. Hasil uji autokorelasi.

\begin{tabular}{rrrrrc}
\hline Model & $\mathrm{R}$ & R Square & $\begin{array}{l}\text { Adjusted } \\
\text { R Square }\end{array}$ & $\begin{array}{c}\text { Std. Error Of } \\
\text { the Estimate }\end{array}$ & $\begin{array}{c}\text { Durbin- } \\
\text { Watson }\end{array}$ \\
\hline 1 & 0,505 & 0,256 & 0,192 & 7,56164 & 1,566 \\
\hline
\end{tabular}

Sumber: Pengolahan Data Primer Tahun 2013.

Berdasarkan Tabel 4 terlihat bahwa

nilai D adalah sebesar 1,566.

Dikarenakan nilai D 1,566 terletak antara
1,5 sampai 2,5 maka dapat disimpulkan bahwa model regresi yang dibentuk tidak mengalami autokorelasi.

Model Regresi Linier Berganda

Hasil analisis regresi yang yang diduga mempengaruhinya dianalisis memperhitungkan hubungan antara produktivitas usahatani Padi Ciherang dengan variabel peubah atau variabel bebas dengan menggunakan software SPSS versi 15. Untuk lebih jelasnya dapat dilihat pada Tabel 4 berikut ini :

Tabel 5. Faktor- faktor yang mempengaruhi produktivitas usahatani Padi Ciherang

\begin{tabular}{lccccc}
\hline Variabel & $\begin{array}{l}\text { Koefisien } \\
\text { Regresi }\end{array}$ & Std. Eror & T hitung & Sig & VIF \\
\hline Konstanta & 46,345 & 3,512 & 13,197 & 0,000 & \\
Luas lahan & 1,039 & 4,476 & 0,232 & 0,817 & 6,136 \\
Benih & $-0,068$ & 0,068 & $-0,994$ & 0,325 & 7,173 \\
Pupuk & 0,087 & 0,030 & 2,890 & 0,006 & 1,640 \\
Pestisida & 0,196 & 0,183 & 1,069 & 0,290 & 1,710
\end{tabular}

Sumber: Pengolahan Data Primer Tahun 2013 
Berdasarkan hasil analisis regresi pada Tabel 5 tersebut diperoleh model regresi linier berganda sebagai berikut:

Pr $=b_{0}+b_{1}$ Lh $-b_{2}$ Bnh $+b_{3}$ Ppk $+b_{4}$ Pest $\mathrm{Pr}=46,345+1,039 \mathrm{Lh}-0,068 \mathrm{Bnh}+$ 0,087 Ppk + 0,196 Pest

Dimana: $\operatorname{Pr}=$ Produktivitas Padi Ciherang ( kw/ha)

$$
\begin{aligned}
& \text { b0 }=\text { Intersep } \\
& \text { Lh }=\text { Luas lahan (ha) } \\
& \text { Bnh }=\text { Benih }(\mathrm{kg}) \\
& \text { Ppk }=\text { Pupuk }(\mathrm{kg}) \\
& \text { Pest }=\text { Pestisida (Ltr) }
\end{aligned}
$$

Model regresi linier berganda tersebut dapat diinterpretasikan sebagai berikut:

a. Koefisien regresi variabel luas lahan sebesar 1,039 menunjukkan bahwa setiap terjadi penambahan luas lahan sebesar 1\% maka akan meningkatkan produktivitas Padi Ciherang sebesar $1,039 \%$.

b. Koefisien regresi variabel benih sebesar -0,068 menunjukkan bahwa setiap terjadi penambahan jumlah benih sebesar $1 \%$ maka akan menurunkan produktivitas Padi Ciherang sebesar $0,068 \%$.

c. Koefisien regresi variabel pupuk sebesar 0,087 menunjukkan bahwa setiap terjadi penambahan jumlah pupuk sebesar $1 \%$ maka akan meningkatkan produktivitas Padi Ciherang sebesar 0,087 \%.

d. Koefisien regresi variabel pestisida sebesar 0,196 menunjukkan bahwa setiap terjadi penambahan jumlah pestisida sebesar $1 \%$ maka akan meningkatkan produktivitas Padi Ciherang sebesar $0,196 \%$.

\section{Uji Statistik F (Uji Serentak)}

Uji $\mathrm{F}$ digunakan untuk menunjukkan apakah semua variabel independen yang dimasukkan dalam model memiliki pengaruh secara bersama-sama terhadap variabel dependen. Hasil uji $\mathrm{F}$ dapat dilihat melalui nilai $F$ hitung dan nilai signifikan $F$ pada Tabel 6 berikut ini:

Tabel 6. Hasil uji statistik F

\begin{tabular}{llrrrrr}
\hline Model & Sum Of Squares & Df & Mean Square & F & Sig. \\
\hline 1 & Regression & 922,274 & 4 & 230,568 & 4,032 & $0,007^{\mathrm{a}}$ \\
Residual & 2687,387 & 47 & 57,178 & & \\
Total & 3609,660 & 51 & & & \\
\hline
\end{tabular}

Sumber: Pengolahan Data Primer Tahun 2013.

Dari Tabel 5 pada uji statistik F tersebut diketahui bahwa nilai $\mathrm{F}$ hitung sebesar 4,032 dengan nilai signifikan F sebesar 0,007. Jadi nilai signifikan $\mathrm{F}$ sebesar $0,007<0,05$ sehingga $\mathrm{HO}$ ditolak dan $\mathrm{Ha}$ diterima. Artinya semua variabel yang dianggap mempengaruhi yaitu variabel luas lahan, benih, pupuk dan pestisida secara simultan atau bersama-sama berpengaruh nyata terhadap produktivitas usahatani Padi Ciherang.

Koefisien Determinasi $\left(\mathrm{R}^{2}\right)$

Nilai koefisien determinasi $\left(\mathrm{R}^{2}\right)$ dalam penelitian ini dapat dilihat pada Tabel 7 berikut ini:

Tabel 7. Hasil koefisien determinasi.

\begin{tabular}{ccccc}
\hline Model & R & R Square & Adjusted R Square & Std. Error of the Estimate \\
\hline 1 & $0,505^{\mathrm{a}}$ & 0,256 & 0,192 & 7,56164 \\
\hline
\end{tabular}

Sumber: Pengolahan Data Primer Tahun 2013.

Besarnya pengaruh variabel luas lahan, benih, pupuk dan pestisida secara keseluruhan dapat dilihat melalui nilai Adjusted $\mathrm{R}^{2}$ yaitu sebesar 0,192. Hasil tersebut menunjukan bahwa pengaruh variabel luas lahan, benih, pupuk dan pestisida terhadap produktivitas usahatani Padi Ciherang adalah sebesar 19,2 \% dan 
$80,8 \%$ dipengaruhi oleh variabel lain yang tidak termasuk dalam model regresi.

Uji Statistik t (Uji Individual/Parsial)

Uji $t$ dilakukan untuk mengetahui apakah variabel-variabel independen dapat mempengaruhi variabel dependen, oleh karena itu diperlukan pengujian statistik secara parsial. Dengan dilakukannya uji t ini maka akan diketahui apakah variabel luas lahan, benih, pupuk dan pestisida secara parsial berpengaruh nyata terhadap produktivitas usahatani Padi Ciherang. Hasil uji t dapat dilihat pada Tabel 8 berikut ini.

Tabel 8. Hasil uji statistik t

\begin{tabular}{lcc}
\hline Variabel & T hitung & Sig. \\
\hline Luas lahan & 0,232 & 0,817 \\
Benih & $-0,994$ & 0,325 \\
Pupuk & 2,890 & 0,006 \\
Pestisida & 1,069 & 0,290
\end{tabular}

Sumber: Pengolahan Data Primer Tahun 2013.

Berdasarkan uji parsial pada Tabel 7 tersebut diperoleh pengaruh masing-masing variabel sebagai berikut:

a. Luas Lahan

Hasil pengujian uji statistik $t$ variabel luas lahan menunjukan bahwa nilai thitung sebesar 0,232 dengan nilai signifikan t sebesar 0,817 . Jadi nilai signifikan $\mathrm{t}$ sebesar $0,817>0,05$, sehingga $\mathrm{HO}$ diterima dan Ha ditolak. Artinya secara parsial variabel luas lahan berpengaruh tidak nyata terhadap produktivitas Padi Ciherang.

b. Benih

Hasil pengujian uji statistik $t$ variabel benih menunjukan bahwa nilai t hitung sebesar $-0,994$ dengan nilai signifikan $t$ sebesar 0,325. Jadi nilai signifikan $\mathrm{t}$ sebesar $0,325>0,05$, sehingga $\mathrm{HO}$ diterima dan Ha ditolak. Artinya secara parsial variabel benih berpengaruh tidak nyata terhadap produktivitas Padi Ciherang.

c. Pupuk

Hasil pengujian uji statistik $t$ variabel pupuk menunjukan bahwa nilai t hitung sebesar 2,890 dengan nilai signifikan $\mathrm{t}$ sebesar 0,006 . Jadi nilai signifikan $\mathrm{t}$ sebesar $0,006<0,05$, sehingga $\mathrm{H} 0$ ditolak dan $\mathrm{Ha}$ diterima. Artinya secara parsial variabel pupuk berpengaruh nyata terhadap produktivitas Padi Ciherang.

d. Pestisida

Hasil pengujian uji statistik t variabel pestisida menunjukan bahwa nilai t hitung sebesar 1,069 dengan nilai signifikan t sebesar 0,290. Jadi nilai signifikan $t$ sebesar $0,290>0,05$, sehingga H0 diterima dan Ha ditolak. Artinya secara parsial variabel pestisida berpengaruh tidak nyata terhadap produktivitas Padi Ciherang.

Produktivitas Usahatani Padi Ciherang di

Desa Hambuku Hulu

Total produksi usahatani Padi Ciherang yang dibudidayakan oleh petani responden di Desa Hambuku Hulu adalah 4163,5 Kw dengan produktivitas rata-rata $46,74 \mathrm{Kw} / \mathrm{ha}$. Rata-rata luas lahan, total produksi dan produktivitas usahatani Padi Ciherang di Desa Hambuku Hulu dapat dilihat pada Tabel 9 berikut ini:

Tabel 9. Rata-rata luas lahan, total produksi dan produktivitas usahatani Padi Ciherang di Desa Hambuku Hulu.

\begin{tabular}{cclc}
\hline No & Usahatani Padi Ciherang & Jumlah & Rata-rata \\
\hline 1 & Luas Lahan & $87,5 \mathrm{Ha}$ & $1,68 \mathrm{Ha}$ \\
2 & Total Produksi & $4163,5 \mathrm{Kw}$ & $80,06 \mathrm{Kw}$ \\
3 & Produktivitas & $2430,68 \mathrm{Kw} / \mathrm{ha}$ & $46,74 \mathrm{Kw} / \mathrm{ha}$ \\
\hline
\end{tabular}

Sumber: Pengolahan Data Primer Tahun 2013 
Produksi rata-rata pada Tabel 9 diperoleh dari hasil bagi antara total produksi dengan seluruh jumlah responden, sedangkan produktivitas rata-rata bisa diperoleh dengan cara membagi antara total produktivitas dengan jumlah seluruh responden yang menghasilkan 46,74 Kw/ha. Tetapi produktivitas bisa juga dihitung dengan membagi hasil rata-rata produksi (output) dibagi dengan rata-rata luas lahan (input), yaitu dengan rumus:

\section{KESIMPULAN}

Faktor- faktor yang dianggap mempengaruhi produktivitas usahatani padi Ciherang yaitu luas lahan, benih, pupuk dan pestisida secara simultan berpengaruh nyata terhadap produktivitas usahatani Padi Ciherang. Berdasarkan hasil uji $\mathrm{t}$ (uji parsial/individual), sedangkan faktor- faktor yang berpengaruh nyata terhadap produktivitas usahatani Padi Ciherang adalah

\section{DAFTAR PUSTAKA}

Dinas Pertanian Tanaman Pangan dan Hortikultura Kabupaten Hulu Sungai Utara. 2012. Laporan Tahunan. Amuntai.

Balai Penyuluhan Kecamatan Sungai Pandan. 2012. Produksi dan Produktivitas Padi Kecamatan Sungai Pandan Tahun 2012. Alabio.

$$
\begin{aligned}
\mathrm{PR} & =\frac{\mathrm{Y}}{\mathrm{X}} \\
& =\frac{80,06 \mathrm{Kw}}{1,68 \mathrm{Ha}} \\
& =47,65 \mathrm{Kw} / \mathrm{ha} \\
& \text { Berdasarkan hasil perhitungan }
\end{aligned}
$$
tersebut, rata-rata produktivitas usahatani Padi Ciherang di Desa Hambuku Hulu adalah 46,74 Kw/ha dapat dikatakan berproduktivitas baik dengan rata-rata produksi 80,06 $\mathrm{Kw}$ dan rata-rata luas lahan 1,68 ha.

variabel pupuk, sedangkan variabel luas lahan, benih dan pestisida berpengaruh tidak nyata terhadap produktivitas usahatani Padi Ciherang dan rata-rata produktivitas usahatani Padi Ciherang di Desa Hambuku Hulu adalah 46,74 Kw/ha dapat dikatakan berproduktivitas baik dengan rata-rata produksi 80,06 $\mathrm{Kw}$ dan rata-rata luas lahan 1,68 Ha.

Nazir, M. 2005. Metode Penelitian. Ghalia Indonesia. Jakarta.

Pratiwi, N. 2012. Faktor-Faktor yang mempengaruhi produktivitas jagung di Desa Pulau Damar Kecamatan Banjang Kabupaten Hulu Sungai Utara. Skripsi Program Studi Agribisnis Sekolah Tinggi Ilmu Pertanian. Amuntai.

Sinungan, M. 2008. Produktivitas Apa dan Bagaimana. Bumi Aksara. Jakarta. 